\title{
Velimír Khlébnikov: para além da poesia*
}

\section{Mário Ramos Francisco Júnior**}

RESUMO: A partir de observações sobre aspectos formais, temáticos e filosóficos característicos da poética de Velimír Khlébnikov, e da inserção de sua criação no contexto das vanguardas russas do início do século $X X$, este artigo tem como objetivo apresentar e abordar exemplos de sua produção em prosa, texto dramático e ensaio. Khlébnikov é bastante conhecido no Ocidente por sua produção lírica e seu trabalho com outros gêneros ainda é pouco estudado e traduzido em língua portuguesa.
ABSTRACT: Based on formal, thematic and philosophical aspects characteristic of Velimir Khlebnikov's poetics, and on the insertion of his creations in the context of the Russian avant-garde, this article intends to present and approach examples of his writings in prose, drama and essays. Although Khlebnikov is quite known in the West as a lirical writer, his work in other genres is still to be more studied and translated into portuguese.

PALAVRAS-CHAVE: Velimír Khlébnikov, vanguarda, literatura russa, prosa, texto dramático, ensaio.

KEY-WORDS: Velimír Khlébnikov, avant-garde, Russian literature, prose, drama, essay. 
* Este artigo é resultado parcial de pesquisa realizada com apoio da Fapesp.

** Professor de Literatura Russa no curso de graduação em russo e na área de pós-graduação em Literatura e Cultura Russa da Faculdade de Filosofia, Letras e Ciências Humanas da USP

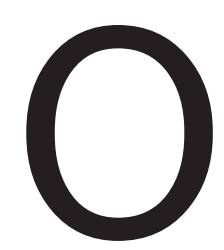

escritor russo Velimír Khlébnikov (1885-1922) é conhecido no Brasil (ou em língua portuguesa), principalmente, como poeta. Alguns de seus trabalhos com o verso, tanto lírico quanto narrativo, já foram traduzidos em português por grandes tradutores e especialistas em literatura russa ${ }^{1}$. O foco de interesse na produção lírica do escritor é absolutamente compreensível, já que até mesmo seus contemporâneos chamavam a atenção para a qualidade de seu trabalho poético: o mais conhecido poeta das vanguardas russas, Vladímir Maiakóvski, o considerava "um dos nossos mestres em poesia" e "magnífico e honestíssimo paladino de nossa luta poética"2, assim como o linguista Roman Jakobson o consideraria o maior poeta da primeira metade do século XX no mundo. Dos poucos ensaios produzidos por especialistas brasileiros sobre o autor, um dos mais famosos é "O Colombo dos Novos Continentes Poéticos"3, de Augusto de Campos, no qual está transcrita aquela que talvez seja a tradução mais conhecida entre os leitores brasileiros de um poema de Velimír Khlébnikov, no caso, A Encantação pelo Riso, de 1910:

\footnotetext{
1 Em língua portuguesa, o leitor tem acesso a poemas traduzidos nas seguintes publicações: Poesia Russa Moderna (org. e trad. de Boris Schnaiderman, Augusto e Haroldo de Campos, São Paulo: Perspectiva, 1968), Poemas de Khliébnikov (org., tradução e comentários de Marco Lucchesi, Niterói: Cromos, 1993), Sempre, Para Sempre, Lá e Cá - poemas de Velimir Khlébnikov (trad. de Aurora Bernardini, Florianópolis: Katarina Kartonera, 2010). Os únicos exemplos da prosa de Khlebnikov em língua portuguesa são o conto "Ka" (acompanhado de um estudo sobre sua obra, em tradução de Aurora Bernardini, São Paulo: Perspectiva, 1977) e o conto "Dia de Páscoa" (trad. de Mário Ramos, na Nova Antologia do Conto Russo, São Paulo: Editora 34, 2010).
}

${ }^{2}$ No artigo "V. V. Khliébnikov", de 1922, ano da morte de Khlébnikov, publicado em português
em A Poética de Maiakóvski (SCHNAIDERMAN, Boris, São Paulo: Perspectiva, 1971)

${ }^{3}$ Augusto de Campos, "0 Colombo dos Novos Continentes Poéticos",1989, pp. 87-95. 


\author{
Ride, ridentes! \\ Derride, derridentes! \\ Risonhai aos risos, rimente risandai! \\ Derride sorrimente! \\ Risos sobrerrisos - risadas de sorrideiros risores! \\ Hílare esrir, risos de sobrerridores riseiros! \\ Sorrisonhos, risonhos, \\ Sorride, ridiculai, risando, risantes, \\ Hilariando, riando, \\ Ride, ridentes! \\ Derride, derridentes! $!^{4}$
}

Na verdade, Khlébnikov foi um dos mais importantes pensadores da estética de vanguarda na Rússia. Sua concepção temática e formal de uma estética de vanguarda está presente em textos literários de diversos gêneros e em seus ensaios e cartas, sempre filtrada por sua visão poética do mundo. Um exemplo de como o trabalho com a linguagem interferia em todos os níveis da concepção de mundo do escritor está na criação de seu próprio pseudônimo: na realidade o nome do poeta é Viktor Vladímirovitch Khlébnikov, porém o codinome pelo qual até hoje é conhecido, Velimír (e não Velímir, como em geral pronuncia-se no ocidente), é um neologismo formado pelas palavras velíkii (em russo, великий: grande, no sentido de grandioso, como em "Pedro, o Grande") e a palavra mir (em russo, мир: mundo ou paz, o que depende do contexto de enunciação).

Apesar de sua importância para o pensamento e a criação na literatura russa do início do século XX, a obra de Khlébnikov foi muito pouco estudada e mesmo publicada durante boa parte do século XX. No dia nove de novembro de 2005, quando eram comemorados, na Rússia, os 120 anos de seu nascimento, em tom de sarcasmo, somado a certa dose de compreensível amargura, o professor e especialista na obra de Khlébnikov,

\footnotetext{
${ }^{4}$ Em Poesia Russa Moderna, 1985, p. 119.
} 
A. E. Parnis, comentava em conferência ${ }^{5}$, em Moscou, sobre o pouco interesse demonstrado na Rússia em uma data tão importante para a arte de vanguarda: "este aniversário de Khlébnikov (no dia 9 de novembro completam-se 120 anos desde o dia do nascimento do poeta) tem sido bastante silencioso. $\mathrm{Na}$ época do pós-modernismo, é difícil despertar o interesse em alguém, ainda que o discurso seja sobre o primeiro Presidente do Globo Terrestre, Velímir Khlébnikov"6. O mencionado título de Presidente do Globo Terrestre, com a grandiloqüência adequada ao nome de seu dono, foi dado a Velimír por seus colegas russos, os budetliánin (neologismo derivado da aglutinação da palavra "budet", verbo ser na terceira pessoa do futuro, somado ao sufixo que é normalmente utilizado para identificar a nacionalidade ou procedência de alguém; deste modo, os budetliánin seriam os "do vir a ser", algo próximo à ideia de "futurista").

De fato, parece estar correto Parnis em seu comentário, pois também pouco combina com um Presidente de tal envergadura, morto em 1922, ter sua primeira biografia completa publicada somente no ainda mais recente ano de 2007, ou seja, 85 anos após sua morte ${ }^{7}$. Segundo a autora da biografia, Sofia Stárkina, apesar das palavras de Maiakóvski sobre Khlébnikov e de publicações de textos de importantes poetas e estudiosos russos sobre o escritor, houve um grande vácuo, entre os anos 30 e meados dos anos 70 e início dos anos 80 , no qual o poeta foi praticamente esquecido no cenário soviético ${ }^{8}$. Este período coincide com o predomínio do realismo socialista sobre as artes na União Soviética, a partir do governo de Stálin. Na década de 90 , ainda de acordo com a autora, há uma inesperada reto-

\footnotetext{
${ }^{5}$ Conferência com participação de especialistas em literatura e filosofia, realizada em homenagem aos 120 anos do nascimento de Khlébnikov, em 20 de dezembro de 2005

${ }^{6}$ PARNIS, A. E.,2005, p. 03.

7 STÁRKINA, Sofia, 2007. Trata-se da primeira biografia completa e do mais recente livro lançado sobre Khlébnikov na Rússia.

${ }^{8}$ Em 1985, eram comemorados os 100 anos do nascimento do poeta e, em 1986, foi lançada a antologia Tvoriéniia (Moscou: Soviétskii Pisátel), com os principais textos de Khlébnikov, incluindo poemas, dramas, contos, supernarrativas, manifestos, artigos e cartas. A partir deste período, (meados dos anos 80), alguns estudiosos dedicados à obra de Khlébnikov puderam publicar em livros pesquisas que já vinham realizando. É o caso do já mencionado A. E. Parnis, além de R. V. Duganov (este, um dos mais importantes especialistas na obra khlébnikoviana), V. P. Grigóriev entre outros. Grigóriev e Parnis foram alguns dos organizadores da antologia Tvoriéniia.
} 
mada do interesse pelo escritor na Rússia, com o surgimento de diversos artigos sobre o poeta, por especialistas de diferentes regiões do país.

Apesar do forte peso do gênero lírico em sua obra, Khlébnikov trabalhou com quase todos os gêneros literários conhecidos e, além disso, realizou experiências no sentido de criar novos gêneros. Não há publicações de novelas ou romances de Khlébnikov, mas há indícios de um suposto texto perdido: em 1929, um grupo de escritores, autodenominado "grupo dos amigos de V. Khlébnikov", publica uma carta aberta, na qual é mencionada a existência de um "romance, em prosa, sobre a vida do tsar Pedro, o Grande, escrito em 1917". O grupo, na carta, chega a oferecer "não menos do que duzentos rublos" pelo manuscrito e por outros, também perdidos, com poemas, trechos de diários e novelas ${ }^{9}$. O fato envolve uma característica biográfica de Khlébnikov: o poeta viajava constantemente pelo território russo e mesmo por países da Ásia Central, carregando seus poemas e anotações em uma grande trouxa (imagem já famosa do poeta no mundo inteiro, visto muitas vezes como um peregrino e um visionário); nestas viagens, Khlébnikov costumava presentear as pessoas que ia conhecendo com seus textos, ou simplesmente abandonava textos pelo caminho, deixando-os nas casas que o hospedavam. 0 texto mencionado até hoje não foi descoberto.

Os contos, textos dramáticos e mesmo ensaísticos são apenas exemplos do importante trabalho de Khlébnikov com outros gêneros literários, para os quais o autor constantemente transporta e conscientemente aplica vários, senão todos, os elementos temáticos e formais utilizados em seus textos líricos. Uma das mais importantes características de sua obra, em geral, é justamente a experiência de fusão de gêneros (e, neste caso, participam dos textos literários até mesmo gêneros não literários, como o ensaio, os estudos de ciências exatas, 0 discurso filosófico puro). Mais do que o simples uso do verso

\footnotetext{
${ }^{9}$ Esta carta não está publicada em nenhuma obra de importância sobre as vanguardas russas. Ela foi descoberta no decorrer desta pesquisa, em visita realizada ao RGALI (Arquivo Estatal Russo de Literatura e Arte), em Moscou, em 2011. A carta, disponível em microfilme na instituição russa, sob a pasta 527 - doc. 174, foi assinada por vários escritores e estudiosos da época, entre eles, Nikolai Asséiev, Óssip Brik, Alekséi Krutchônikh e Vladímir Maiakóvski.
} 
ou de recursos estilísticos da poesia em contos ou textos dramáticos, Khlébnikov permite que elementos estruturais de um gênero atuem e "deformem ${ }^{10 "}$ outros gêneros, alterando assim seu princípio de construção. O ponto culminante destas experiências foi a geração de um possível novo gênero, que o poeta denominou de "supernarrativa".

O último texto literário de Khlébnikov, escrito entre 1919 e 1921, foi o exemplo mais bem acabado da ideia de "supernarrativa". Intitulado Zanguézi, a supernarrativa é composta por 21 partes (que o autor denomina como "planos"), que podem ser abordadas isoladamente, mas que também são importantíssimas para a obtenção da unidade do texto completo. Em Zanguézi, o profeta Zanguézi, desacreditado por seus ouvintes (o nome do poeta já é um exercício poético, já que é formado a partir dos nomes de dois rios, o Ganges e o Zambezi, simbolizando a união impossível entre a Ásia e a África), apresenta em sua saga todos os preceitos de criação poética elaborados pela vanguarda russa até ali (e também pela tradição literária russa, muitas vezes). Zanguézi também se apresenta como uma personagem autobiográfica, trazendo em suas características muitos elementos presentes na biografia do autor e sua relação com seus ouvintes remete diretamente às críticas que Khlébnikov recebia por seus trabalhos literários e estudos (muitos destes estudos consistiam em tentativas de elaboração de profecias, por meio de cálculos matemáticos). Em Zanguézi convivem diferentes formas e gêneros que auxiliam na composição de seus planos e são fundamentais para a obtenção da unidade artística. A própria "introdução", já uma das partes internas do texto, é apresentada na forma de um pequeno ensaio que explica, dentro da supernarrativa, o conceito deste gênero (dentro do breve comentário, a princípio a exposição de um conceito, o autor utiliza algumas metáforas, já típicas de um texto literário:

Uma narrativa é construída com palavras, como a construção de um edifício por unidades. As palavras isométricas servem à unidade como pequenas pedras. A supernarrativa, ou transnarrativa, constitui-se de fragmentos

\footnotetext{
10 Aqui, o termo "deformação" é utilizado no sentido que lhe é dado pelos teóricos do chamado formalismo russo, principalmente, Iuri Tynianov: em seus estudos sobre o princípio de construção do texto literário, ele aplica o termo para definir o quanto um elemento subordinante em um texto artístico pode deformar os elementos subordinados em sua forma.
} 
independentes, cada qual com seu deus especial, sua fé especial e sua regra especial. (...) Construindo-se a unidade, a pedra da supernarrativa, tem-se a novela de primeira ordem. A supernarrativa é parecida com uma escultura de blocos multicoloridos de diferentes tipos: o corpo, de pedra branca; a capa e a roupa, de azul; os olhos, de negro. Ela é trabalhada nos blocos multicoloridos da palavra, em suas diferentes estruturas. Encontra-se, assim, um novo tipo de trabalho no campo da articulação do tema. A narrativa é a arquitetura das palavras. A arquitetura das narrativas é a supernarrativa. Para o artista, o que lhe serve de bloco não é mais a palavra, mas a narrativa de primeira ordem."

E se o convívio de textos de diferentes formas e gêneros é essencial para a unidade e estabilidade da supernarrativa, uma das características fundamentais dos textos em prosa apresentados nesta coletânea é justamente o caminho inverso: a intromissão de uns gêneros sobre os outros, alterando sua estrutura e desestabilizando-a, o que leva ao inevitável questionamento sobre sua cristalização na tradição literária. Para isso, a própria tradição literária, considerada no sistema mais amplo da literatura russa, deve estar também presente.

Khlébnikov propõe, assim, uma renovação dos gêneros a partir de sua relação com a tradição e da desestabilização de suas estruturas, com o trabalho sobre seus elementos fundamentais (no conto, atuando sobre a fábula, o enredo, o espaço, o tempo, a construção das personagens; no drama, sobre o desenvolvimento dos atos, a catarse, as funções das falas e das personagens; no ensaio, sobre o desenvolvimento lógico de conceitos, entremeados por recursos poéticos e linguísticos que, a princípio, o "desautorizaria" em sua função principal).

O cimento que une os blocos da supernarrativa e que está presente em quase todos os seus textos em prosa é o elemento formal mais inovador das vanguardas russas, talvez um dos mais inovadores de todas as vanguardas no mundo: a utilização da chamada língua zaúm ou língua transmental, inicialmente mais presente em textos líricos do autor e de outros escritores das vanguardas russas.

Muitos experimentos com a linguagem foram realizados por diferentes vanguardas, no contexto europeu. Um dos exem- 
plos mais conhecidos foi o procedimento de escolhas aleatórias para a formação de textos artísticos inovadores do dadán, que se apropriou muitas vezes das reduplicações imitativas dos primeiros murmúrios emitidos pelas crianças e utilizava a seleção de palavras para o texto literário a partir de recortes de jornal recortados e tirados de um "saco de palavras". Um método no qual a participação do acaso era fundamental para a criação. Na criação da linguagem transmental, do zaúm de Khlébnikov e Krutchônikh, os cubofuturistas valeram-se da linguagem infantil e de tantos outros recursos, na tentativa de elaborar uma nova língua. Neste caso específico, o caráter de experimentação, de inovação e de invenção do movimento cubofuturista russo levou, pouco a pouco, à radicalização das propostas iniciais para a concepção da língua transmental, apontando em direção ao abstracionismo completo, com experiências que chegavam ao desligamento quase completo entre significante e significado. O poema $A$ Encantação pelo Riso, apresentado acima, traz apenas uma das formas da língua zaúm: o uso de neologismos compostos pela articulação de sufixos e prefixos inusitados em sua ligação com determinadas raízes de palavras. Portanto, um método de construção de língua transmental (chamaremos, aqui, sempre de língua zaúm) que se apropria da estrutura morfológica da língua russa.

A concepção de língua transmental apresentada por Alekséi Krutchônikh na "Declaração da Língua Transmental" ("Deklarátsiia Zaúmnovo Iazyká", Revista Iskusstvo, 1920-1921) apresenta conceitos bastante complexos e sistematizados sobre o zaúm. Logo no primeiro parágrafo do manifesto, surge uma contradição de base sobre a nova língua experimental, contradição de extrema importância para a compreensão dos experimentos zaúm dentro do movimento de vanguarda russo: a língua transmental nasce como uma criação coletiva, como a maior parte das inovações de vanguarda, mas é, ao mesmo tempo, nas palavras de Krutchônikh, "uma língua pessoal (o autor é indivíduo)"12. Estão à disposição da língua transmental construções linguísticas que possam representar estados

\footnotetext{
11 Movimento fundado em 1916, no Cabaret Voltaire, em Zurique, por Tristan Tzara, Hugo Ball, Richard Huelsenbeck e outros artistas.

12 KRUTCHÔNIKH, Aleksei. "Declaração da Língua Transmental" in: Poesia Sonora - Poéticas experimentais da voz no século XX, 1992, pp. 30-32.
} 
emocionais, linguagem infantil, topônimos e antropônimos, além de outros que serão agregados mais adiante no manifesto, como os cantos mágicos, os encantamentos, os sotaques específicos, os lapsos ou erros casuais, que se manifestam pela linguagem. Em outras palavras, dentro de um sistema mais aberto e generalizado elaborado inicialmente para o zaúm pelo grupo, cada autor pode criar seu próprio zaúm, inclusive com seu sistema próprio, como faz Khlébnikov em Zanguézi. Mais do que dizer que cada autor inventa sua própria língua transmental, poderíamos afirmar que em cada poema zaúm há uma nova forma da língua transmental em manifestação. No zaúm de Khlébnikov, a retomada de elementos folclóricos associada à aproximação das estruturas da linguagem infantil, o uso constante de neologismos e, principalmente, a criação de palavras e discursos com estruturas fonéticas quase que destituídas de sentido, em muitos casos levaram à associação dos termos "infantilismo" ou "primitivismo" à sua poética, o que de nenhuma maneira soa como uma rotulação pejorativa. A principal diferença entre estes recursos e o exemplo de aleatoriedade dadá mencionado consiste em um processo de criação que pressupõe o domínio racional sobre a linguagem (tanto a nova língua, quanto a língua russa e outras línguas que participam do processo) para a criação de neologismos que, em sua maioria, não buscam o afastamento do sentido, mas a geração de novos sentidos a partir dos originariamente embutidos nos fragmentos morfológicos (ou sintáticos) utilizados. Uma breve observação de versos como "ride, ridentes! Derride, derridentes!" já permite observar este recurso de geração de sentidos em novas palavras, baseados nos sentidos originais contidos em palavras ou elementos morfológicos. E a ampliação dos sentidos a partir do trabalho com a linguagem, com a morfologia, a sintaxe e a semântica da língua, está presente na maior parte dos textos mais criativos de Khlébnikov, às vezes como recurso dominante do texto (como no texto dramático "Os Deuses"), às vezes despontando como elemento surpresa (como em muitos dos contos e mesmo nos ensaios, em que trata do próprio fazer poético, por exemplo, "Sobre a Poesia Contemporânea").

É possível de dizer que há uma postura literária em Khlébnikov que perpassa toda sua obra, a saber, a tentativa menos 
de romper e mais de eliminar fronteiras, torná-las permeáveis. A realização desta tarefa faz com que o poeta esteja sempre postado justamente na fronteira entre dois campos, que podem dizer respeito a vários âmbitos: gêneros, formas, linguagens, escolas literárias, espaço e tempo, personagens, discurso etc. Esta característica foi determinante para a seleção dos textos aqui apresentados, ainda que esteja presente em grande parte da obra do autor. No plano da observação teórica, estamos tratando a ideia de fronteira aqui como um conceito, mais precisamente, um conceito semiótico. O semioticista russo Iuri Lótman (1922-1993), um dos criadores da linha denominada "semiótica da cultura", a partir do conceito de biosfera (campo da vida orgânica e biológica), desenvolve junto a outros semioticistas o conceito de "semiosfera": se a "semiótica da cultura" estuda o campo das relações entre sistemas no plano da cultura, a "semiosfera" seria o espaço no qual os fenômenos da série cultural são observados ${ }^{13}$. O conceito de semiosfera de Lótman (junto aos conceitos internos de sistemas semióticos, espaços semióticos e fronteira) permite abordar e estudar, na estrutura dos textos de Khlébnikov as relações entre os diferentes sistemas semióticos ali articulados. Estas articulações

\footnotetext{
${ }^{13} 0$ conceito de semiosfera de Lótman refere-se à cultura e suas várias ramificações, estabelecendo delineamentos e zonas de restrição que o linguista chama de "espaços semióticos". Em termos mais concretos e práticos, o espaço que corresponde à semiosfera (ou seja, ao universo da cultura) é formado por distintos espaços semióticos em interação constante, como aqueles formados pelas linguagens e textos e os formados por outras séries culturais, como as artes, a mitologia, as religiões e outros. De fato, todos estes espaços semióticos representam sistemas de diferentes tipos e níveis. Sobre os sistemas semióticos, Lótman diz que "como ahora podemos suponer, no existen por sí solos en forma aislada sistemas precisos y funcionalmente unívocos que funcionan realmente. La separación de estos está condicionada únicamente por una necesidad heurística. (...) Sólo funcionan estando sumergidos en un continuum semiótico, completamente ocupado por formaciones semióticas de diversos tipos y que se hallan en diversos niveles de organización. A ese continuum, por analogía con el concepto de biosfera introducido por V. I. Vernádski, lo llamamos semiosfera. (...) el espacio de la semiosfera tiene un carácter abstrato. Esto, sin embargo, en modo alguno significa que el concepto de espacio se emplee aquí en un sentido metafórico. Estamos tratando con una determinada esfera que posee los rasgos distintivos que se atribuyen a un espacio cerrado en sí mismo. Sólo dentro de tal espacio resultan posibles la realización de los procesos comunicativos y la producción de nueva información". O conceito de semiosfera torna-se muito mais complexo e dinâmico quando observado nas relações entre diferentes sistemas semióticos. Envolvidos em seus espaços semióticos específicos, estes sistemas se inter-relacionam em suas zonas de fronteira. Segundo Lótman, a fronteira é um sistema de extrema importância para a estrutura da semiosfera. Ela é "un mecanismo bilingüe que traduce los mensages externos al lenguaje interno de la semiosfera y a la inversa".
} 
vão desde as relações entre a língua russa e a linguagem zaúm em seus vários níveis até as que se estabelecem entre os espaços semióticos culturais no interior da estrutura dos gêneros e formas, ou mesmo as relações que articulam diferentes séries culturais, como as artes e a ciência com a literatura e diferentes sistemas literários ${ }^{14}$. Da remoção da fronteira da língua até a das fronteiras entre prosa, poesia, drama, ensaio, tradição e inovação, cultura e história russa e outras culturas e histórias.

Estas características, associadas à profundidade poética do olhar de Khlébnikov sobre o mundo a sua volta, sobre a literatura de seu tempo e a tradição, fizeram dele o "mestre" dos escritores da vanguarda russa. Tendo participado dos primeiros agrupamentos de vanguarda, na Rússia, sua produção poética já se inicia antes deles (e já com traços de profunda inovação no plano da linguagem), em 1907, ainda sob certa influência do Simbolismo. E o escritor desponta como um dos principais mentores de um grupo que seria um embrião do chamado cubofuturismo russo, o grupo Guileia. Ali tem início o profícuo trabalho coletivo da vanguarda russa, ainda em 1910, com a publicação de um almanaque intitulado Armadilha para Juízes (em russo, Sadók sudiéi). Naquele momento, o grupo contava com quatro poetas: David Burliuk, Vassíli Kamiénski, Viktor Khlébnikov (só depois ele adotaria o pseudônimo Velimír) e Elena Gurô. (de quase todos temos alguns exemplos de traduções para a língua portuguesa, e quase todos em Poesia Russa Moderna, obra já aqui mencionada, menos de Elena Gurô). Eram escritores que, fundamentalmente, trabalhavam com a poesia, com o gênero lírico. Porém, a literatura em prosa produzida naquele período foi de grande importância para a vanguarda e

\footnotetext{
14 Em termos mais práticos, as traduções entre linguagens seriam fenômenos de fronteira para estes sistemas (sejam traduções entre línguas ou entre diferentes formas de linguagem, como as formas artísticas, por exemplo). Porém, é possível observar também tal mecanismo, não no nível das linguagens, no dos sistemas culturais. Lótman fornece um exemplo bastante concreto: "lá valoración de los espacios interior y exterior no es significativa. Significativo es el hecho mismo de la presencia de una frontera. Así, en las robinsonadas del siglo XVIII, el mundo de los 'salvages' que se halla fuera de la semiótica de la sociedad civilizada (pueden equipararse a él los mundos de animales o de niños, construidos de manera igualmente artificial - con arreglo al rasgo distintivo del estar situado fuera de las 'convenciones' de la cultura, es decir, de los mecanismos semióticos de ésta), es valorado positivamente". As citações sobre o conceito de semiosfera foram extraídas da tradução para o espanhol elaborada por Desiderio Navarro, em I. M. Lótman, La Semiosfera (vols. I e II), Madrid: Cátedra, 1996. Os fragmentos transcritos nesta nota referem-se às páginas 23 a 29 do primeiro volume, no capítulo "Acerca de la Semiosfera".
} 
trazia uma grande variedade de aspectos de inventividade em diferentes níveis. E muitos destes aspectos (como o trabalho com a linguagem, o uso de neologismos, os recursos sonoros) foram transportados à prosa a partir de experimentos realizados em textos líricos, de forma coletiva. Há indicações, em estudos sobre cartas e manifestos de vanguarda, de que tanto a língua zaum, quanto os contos curtos e microtextos dramáticos de Khlébnikov teriam sofrido a influência de criações semelhantes de Elena Gurô, morta prematuramente aos 36 anos, em 1913.

Após o longo período do século XX em que Khlébnikov foi pouco publicado e estudado, dos anos 30 até a década de oitenta, o autor voltou a despertar o interesse de críticos e estudiosos de literatura na Rússia e em outros países. Se, já no ano de 2005 , o especialista na obra do poeta, E. Parnis, reclamava mais atenção a um escritor de tal importância para sua literatura, justamente a partir daqueles anos do início do século XXI, o interesse por sua obra começou a crescer rapidamente.

Até o final do século passado, os estudos mais importantes sobre a obra do escritor estavam restritas a um número pequeno de especialistas, como N. L. Stepánov, V. P. Grigóriev, R. V. Dugánov (este considerado até hoje o principal especialista em sua obra), além de publicações e traduções de críticos estrangeiros, principalmente dos Estados Unidos da América. Os estudos de críticos como Dugánov ou Stepánov estavam principalmente voltados para a análise das características da produção lírica e das supernarrativas de Khlébnikov, como foco de interesse nas temáticas abordadas em suas obras e, claro, na utilização dos recursos oferecidos pela língua zaúm. Assim, uma grande parte desses estudos abordava, em Khlébnikov, o poeta da linguagem. Pode-se dizer que o maior volume de materiais variados que tratem da obra do escritor é muito recente, mesmo na Rússia.

Já nos últimos anos, é perceptível o crescente interesse de pesquisadores pela produção ensaística, pela prosa e pela produção dramática de Khlébnikov. Entre as várias abordagens observadas atualmente, os estudos apontam principalmente para a originalidade de Khlébnikov ao trabalhar com diversos gêneros, tanto no contexto das vanguardas russas, quanto 
mundiais. Esta originalidade tem relação com o trabalho formal com os gêneros mencionados e a capacidade do escritor de inovar na forma e na linguagem sem perder de vista as influências da tradição literária russa. Neste sentido, apesar de vanguardista, Khlébnikov mostra-se um escritor de fortes tendências clássicas, mesmo na primeira fase de sua produção, no momento mais iconoclasta das vanguardas.

Outro aspecto de sua obra cada vez mais estudado atualmente é o desenvolvimento de uma linha filosófica que permeia boa parte dos últimos de seus textos, principalmente seus contos e textos dramáticos. Com base em um tipo de "filosofia racionalista", considerada às vezes aproximada ao pensamento pitagórico ou à filosofia de Leibniz e, às vezes, comparada à filosofia nietzscheana, o poeta desenvolve uma "utopia da harmonia universal". Sua filosofia consistia numa busca pela harmonização dos elementos do universo entre si e do homem com o universo que o cerca. A harmonia universal dependeria de um perfeito equilíbrio entre os elementos do cosmos. Para a obtenção de tal equilíbrio seria necessário o controle total sobre o processo de criação e sobre a estrutura deste cosmos. O poeta transporta essa utopia para o plano estético da palavra que, em si mesma, seria capaz de não só representar o universo, como ao mesmo tempo materializá-lo.

Na criação equilibrada e harmônica da obra de arte e de todos os seus elementos internos e no controle sobre o processo de criação da mesma está a chave da utopia filosófica do poeta. 0 crítico R. V. Dugánov, soube equilibrar, em seus estudos, a análise da questão formal das construções poéticas com a análise da filosofia que se manifesta na obra do poeta. Dugánov assim comenta a relação entre a "palavra" e o "mundo", o "cosmos", a "natureza", na poética de Khlébnikov:

Na mitopoética khlebnikoviana a "palavra" é idêntica à "natureza" e superou a antinomia entre o sentido e sua expressão. (...)

A originalidade, a dificuldade e ao mesmo tempo a convicção desta poesia consistem na apresentação simultânea, diante de nós da declaração poética e da "coisa" 
poética, o princípio poético em sua encarnação completa; a filosofia da "palavra" e o próprio organismo vivo da "palavra", em sua unidade contraditória. (pp. 426-427) ${ }^{15}$

Assim, para Khlébnikov, ontologicamente, a palavra "é" o próprio mundo, e não apenas possui a capacidade de representá-lo. O controle, portanto, do equilíbrio e da perfeição no processo de criação poética é a representação da utopia do controle humano sobre o cosmos, o que se coadunava perfeitamente com a proposta utópica da revolução socialista em seu princípio pré-stalinista: o domínio sobre todos os processos de construção da sociedade levaria, por este princípio utópico, à possibilidade de construção de uma nova nação. Para Khlébnikov, a harmonia somente pode ser alcançada no plano estético, por meio da palavra.

Khlébnikov costumava elaborar, também, cálculos matemáticos em equações complexas, com os quais acreditava poder demonstrar regularidades nos acontecimentos histórico-sociais. Para isso estabelecia relações, muitas vezes, entre os períodos de tempo entre nascimentos e mortes de personalidades importantes para a história universal e para a russa. Também tomava como base para seus cálculos os períodos de tempo entre os grandes fatos da história da humanidade ou, especificamente, da Rússia. Com tais cálculos, acreditava poder prever, baseado nestes ciclos regulares, novos acontecimentos de relevância para a sociedade. Esta vertente de seu trabalho é um dos desdobramentos da linha filosófica que desenvolvia em sua obra, aqui voltada para a ciência como caminho para a previsão e controle sobre os fatos que, futuramente, escreveriam a história da humanidade ${ }^{16}$.

O projeto de elaboração de uma linha filosófica em Khlébnikov, considerando a obra de arte como possibilidade de construção de um universo ideal, assemelha-se muito às con-

\footnotetext{
15 DUGÁNOV, R. V., 974, pp. 418-427.

${ }^{16} \mathrm{O}$ professor V. P. Grigóriev, que dedicou boa parte de sua vida de pesquisador à obra de Velimír Khlébnikov, devido a estas investidas científicas no campo da matemática e tomando como exemplo o fato de que o poeta não somente era capaz de criar um neologismo como empenhava-se em demonstrar filologicamente o processo de criação, definiu-o como "poeta, cientista e pensador" (V. P. Grigóriev, "'Bezúmnyi, no Izumítelnyi'. Velimír Khlébnikov - Nach Einchtein ot Gumanitarii?" [Louco, mas Admirável. Velimír Khlébnikov - Nosso Einstein das Ciências Humanas?], in: AUNIS, número 6, Moscou, 2005, p. 495).
} 
cepções de criação do pintor Pável Filónov (1883-1941), seu contemporâneo e amigo. Os quadros cubofuturistas do pintor, compostos sob um processo diferente do que se via no cubismo da época, partem de imagens fragmentárias de pequenas ruas, como num mapa, que se expandem e fundem-se pouco a pouco, ampliando o campo de visão sobre o que seria uma cidade ou fragmento de cidade. Em muitos casos, a perspectiva distanciada da obra mostra ao apreciador as imagens de rostos ou corpos de seres humanos ou animais fundidos a estas "cidades", ou melhor, nascendo delas, formados pelos pequenos traços que representariam as ruas ou regiões. Filónov chamava seu método de composição de "arte analítica" e considerava que para a compreensão da comunicação entre o seu método e o de Khlébnikov e as antigas teorias até ali, do ponto de vista do diálogo que se estabeleceu entre as obras dos dois artistas, tal comunicação deveria ser observada "em todo o mundo e por todos os séculos da arte, e não através do cubofuturismo ou de Picasso, mas definitivamente através da fria e implacável negação de toda sua mecânica"17.

Para os dois artistas, os elementos de composição de uma obra de arte, seja ela verbal ou não, não seriam, de forma alguma, dependentes uns dos outros, mas integrados uns aos outros, participando ativamente na construção de sentido do conjunto. Este conceito pressupõe a harmonia perfeita entre $o$ homem, sua cultura, o mundo em que está inserido e que por ele é estruturado e, em última instância, a própria forma da obra de arte na qual esta harmonia é representada. No centro do conceito filosófico aplicado por Khlébnikov em sua criação está a idéia do poeta como um "deus", aquele que cria o seu próprio universo na obra artística. No caso específico de Khlébnikov, este pensamento filosófico (baseado também em conceitos elaborados por filósofos russos do final do século XIX) leva, no plano temático, à obsessão pelos temas da morte e do tempo. Vencê-los, dominar o tempo e subverter a morte, seriam resultados de um controle total sobre o processo de criação do próprio universo, levando a um domínio completo não só sobre o passado, mas também sobre o futuro. Como dito acima, esta

\footnotetext{
${ }^{17}$ A. E. Parnis, "O metamorfózakh Mávy. Oliénia i Voiná - k probléme diáloga Khlébnikova i Filónov" ("Sobre as metamorfoses de mava, do cervo e do soldado: para o problema do diálogo de Khlébnikov e Filónov), in: Mir Velimíra Khlébnikova, 2000, p. 637.
} 
luta pela imortalidade e pelo domínio sobre o tempo serão temas constantes de sua prosa e de sua dramaturgia de uma fase mais madura. Estão integrados a este projeto a língua zaúm (possibilitando o domínio sobre um sistema linguístico) e a manipulação dos gêneros (que permite subvertê-los, controlar sua estrutura e processo de criação e gerar um novo gênero).

\section{A prosa khlebnikoviana: reinventando o conto}

A tradição e a importância do conto para a literatura russa remontam ao início do século XIX, no período de consolidação de uma literatura nacional, com Aleksándr Púchkin e Nikolai Gógol. Não à toa, será atribuída a Dostoiévski a famosa afirmação, na segunda metade do século XIX: "todos nascemos de 'O Capote', de Gógol". Se Púchkin havia lançado as bases de uma literatura nacional, quase que sem manifestações em prosa significativas até a segunda década do século XIX, seu contemporâneo Gógol irá experimentar uma ampla gama de temas em seus contos: desde as histórias fantásticas do folclore eslavo até a vida da São Petersburgo de seu tempo, nos contos de temática urbana. Na segunda metade do século XIX, o desenvolvimento do conto russo passa pelas criações de mestres no gênero, como Fiódor Mikhailovitch Dostoiévski e Lev Tolstoi, entre outros. Com o fim deste que foi chamado de "século de ouro" da literatura russa, chega-se ao máximo domínio da elaboração do gênero e o máximo de condensação da narrativa em Antón Tchékhov.

No prefácio ao livro de contos "O Beijo e Outras Histórias", de Tchékhov, Boris Schnaiderman chama o escritor russo de "mestre da narrativa curta", aquele que teria revolucionado o gênero a tal ponto que, depois dele

"o conto curto passou a ter uma nova dimensão interior: sua capacidade de apontar o sentido profundo mesmo de acontecimentos na aparência banais criara uma nova exigência para este gênero literário"18.

${ }_{18}$ TCHEKHOV, A., 2006, pp. 7-10. 
Pode-se afirmar, sem sombra de dúvida, que até 1910, ano das primeiras publicações coletivas de vanguarda (e ano da morte de Tolstói, um dos fatos vistos pelo poeta simbolista Aleksándr Blok como marco do início de uma nova era na cultura russa), a Rússia já possuía uma "tradição do conto" como forma entre os gêneros narrativos, no contexto da literatura universal. Um gênero que segue um percurso muito claro naquela literatura, de seu período de formação, passando pela literatura realista do final do século XIX e desenvolvendo-se até a concisão de Tchékhov, na virada para o século XX. Porém, assim como ocorreu com a maioria dos movimentos de vanguarda no Ocidente, as vanguardas russas apresentavam forte característica iconoclasta, em sua primeira fase. $O$ primeiro manifesto oficial do grupo, intitulado "Bofetada no Gosto do Público", de 1912, traz alguns ataques à tradição, por exemplo: "o passado é estreito. $A$ academia e Púchkin são mais incompreensíveis que hieróglifos" (...) "Lancemos Púchkin, Dostoiévski, Tolstói, etc. do navio de nosso tempo."

Muitos anos depois, o poeta Vladimir Maiakóvski, em seu ensaio "Como Fazer Versos", relativizaria esta postura, afirmando que os escritores da tradição literária russa haviam se cristalizado como monumentos e que (palavras de Maiakóvski) "tirando os monumentos do pedestal, devastando-os e revirando, nós mostramos aos leitores os Grandes por um lado completamente desconhecido e não estudado". A vanguarda russa, portanto, revirava seu cânone no sentido de revisitar e resignificar os autores da tradição. Coube a estes escritores, de um primeiro momento ainda "heroico" do movimento, questionar e repensar o conto (e, em termos mais amplos, a prosa) gerado por toda aquela tradição herdada do século de ouro, agora sob a perspectiva de um período de profundas mudanças (tanto históricas e sociais como estéticas), marcado principalmente pela experimentação.

Sob a influência da invenção sobre a linguagem já utilizada nos primeiros escritos poéticos, os escritores aplicavam recursos típicos da poesia sobre o texto em prosa, rompendo e reformulando as fronteiras entre os gêneros. Já desde 1909, a escritora Elena Gurô reinventava o conto russo, elaborando micronarrativas de pouquíssimos parágrafos, nas quais inseria não somente recursos sonoros da poesia (como rimas, alitera- 
ções, assonâncias), como também implodia a escrita contínua da prosa, fazendo às vezes com que linhas finais dos textos fossem pouco a pouco transformando-se em versos, que se espalhavam pelo branco da página. Elena Gurô, ao brincar com os sons, provocar o estranhamento em relação ao próprio gênero, criar novos adjetivos e substantivos a partir da aplicação de prefixos e sufixos estranhos a determinadas palavras, lançava as bases dos processos criativos que estariam presentes em toda a criação dos cubofuturistas, até o fim dos anos 20 . A seguir, um exemplo de microconto (ou micronarrativa) de Gurô, de $1913^{19}$ :

\section{O gato-naco}

A alma clara do gato clareava no quarto.

Ele tinha uma branca bichanesca barriguinha.

E uma alma bichanesca, pequerrucha, pura, astuta, sábia e bruta.

Por isso um velhusco lustroso quis ensinar o gato a falar, ou a calar o povo e contemplar o mistério...

Chovia. O gatinho cobria o focinho com as patinhas, cobria, cobria e virou Cobritinho.

As crianças acordaram e viram: deitado em sua cama o Cobritinho, um magicolho não dorme, matreiro, verde, e o outro fugiu na frincha de feltro, de pelotudas, veludosas, achatadas patas.

Elena Gurô morreria muito cedo, em 1913. Em muitas das cartas e ensaios dos escritores da época, ela era vista como a primeira mentora do cubofuturismo (considerada responsável pela denominação do primeiro grupo como "Guileia"). A língua zaum, com seus neologismos e exercícios sonoros e que seria mais tarde $o$ aspecto que tornaria a poesia cubofuturista russa conhecida pelo mundo, nasce destes experimentos e passa a influenciar toda a criação de escritores como Alexei Krutchiônikh e Velimír Khlébnikov.

\footnotetext{
${ }^{19}$ A tradução do conto, por Mário Ramos, foi publicada na revista eletrônica Kalinka, em 2013 (http://www.kalinka.com.br/index.php?modulo=Revista\&id=670). Elena Gurô não tem nenhuma tradução publicada no Brasil. Apesar de sua importância como "mentora" dos cubofuturistas russos, também na Rússia seus textos ainda são pouco publicados, porém, tem crescido bastante o número de estudos críticos sobre a autora.
} 
Esse trabalho com o tecido da linguagem, com a superfície textual e também de aproximação entre o gênero narrativo e o gênero lírico surge também, como vimos, nos textos em prosa do poeta Velimír Khlébnikov. Além dos jogos sonoros, da profusão de neologismos e da provocação de rimas internas e ecos no interior das orações, Khlébnikov utilizava outros recursos, como paralelismos, e um narrador muito próximo a um tipo de eu-lírico para elaborar seus próprios microcontos. É o que acontece, por exemplo, no conto sem título (outra característica mais comum na poesia lírica), elaborado em frases curtas que mais lembram longos versos num poema em verso livre, de 1922:

"Eu morri e me pus a rir.

Simplesmente o grande fez-se pequeno, e o pequeno, grande.

Simplesmente em todos os elementos da equação da existência, o sinal "sim" foi ressignificado no sinal "não".

Um fio secreto conduziu-me ao mundo da existência e eu reconheci o Universo na essência da minha esfera sanguínea.

(..)

E então dependurada, disposta entre nuvens, como grotesca listra em celeste azul, que encerrava o estrato da névoa, o éter, monturos estelares.

O só monte estelar em fulgor, como o olho arregalado do átomo.

E compreendi que tudo permanece como sempre esteve, só que eu olho para o mundo contra a corrente.

Eu estou dependurado como um morcego do meu próprio eu.

Eu alcei vôo às origens.

Eu lancei nelas pedaços de papel, fiz tinir as cordas.

Ao notar os sinos amarrados aos fios, puxei por um fio. 
Eu insistia em gritar "ei" por debaixo de um pires, mas ninguém me respondia e então fechei os olhos com as asas e morri pela segunda vez, soluçando: como este mundo é triste!"(1922) ${ }^{20}$

Observada atentamente a proposta do conto (se é que assim pode-se chamá-lo), alguns elementos essenciais da estrutura da narrativa estão ali presentes de forma até mesmo estável e convencional: o enredo, as relações de tempo e espaço etc. A forma do conto e a construção de um narrador que se aproxima da figura lírica da poesia são elementos responsáveis pela desestabilização da estrutura do gênero (o que inclui a ausência de personagens, fato que recorrente em seus microcontos), propondo uma radical renovação desta forma tão cara à tradição literária russa.

Já em ensaio que acompanha a tradução do conto "Ka", de Khlébnikov, conto de 1915, a tradutora Aurora Bernardini aponta para características especiais do método de composição do mosaico mitopoético do conto, no qual se constrói um tipo de "epos universal", e mostra que esse método consiste em destruir as relações de causa e efeito, fragmentar o enredo ao mesmo tempo em que se desintegra a noção de tempo. Em "Ka", o autor russo articula uma série de fragmentos narrativos por meio da articulação de diferentes mitologias, desintegrando o tempo com a aproximação de fatos e personagens históricas a princípio muito distantes em termos cronológicos.

Tanto a criação inovadora sobre os aspectos formais do conto como é conhecido, quanto o uso de neologismos típicos da língua zaúm e os aspecto "infantilista" ou "primitivista" herdado de Elena Gurô (no exemplo acima, com os jogos e tema lúdicos de "Gato-naco"), a recuperação de elementos do folclore apenas com a função de gerar um novo tipo de "conto de fadas" (não mais atrelado à tradição, mas que nasce como uma nova mitologia, gerada no plano da palavra) podem ser observados no conto de Khlébnikov abaixo, também sem título e em sua versão integral, de 1907:

E os seculazes habitam séculos, como certas sereias, cursos d'água. E cada século possui seu seculaz. E se parecem com cisnes de pescoços inclinados e escancaradas

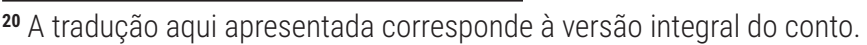


asas de flor de tempo. Ele está então entre flores de azul claro e escuro, como uma clarazulada meia-noite. E tem lábios humanos.

E nas flores, como dos lábios, vivem aromículas: virgens minúsculas na altura e na imagem. Mas suas vestes são gigantescas. E rebelam-se contra uma pessoa próxima, desnuas, agitando suas vestes em redemoinhos, e os tecidos se eroscam e giram e nos roçam e então dizemos: que olor!

E há também outras, castas e pudicas, e é preciso chegar bem perto para conhecê-las. E não se rebelam desnuas.

E quando todas adormecerem, pousará algum dormitador e catará tudo, como um grãozinho, em seu bico...

Em seus contos, Khlébnikov explora frequentemente suas propostas filosóficas, no sentido de buscar, no texto como obra artística, um modelo de unidade harmônica de todos os elementos formais e culturais. Assim, traços primitivos da cultura (mitologia, folclore), a tradição literária, a linguagem, a história da Rússia e de todo o mundo, conferem unidade à obra ao mesmo tempo em que permitem a construção de narrativas inovadoras, de acordo com o espírito das vanguardas. Em Sonho, por exemplo, a observação de uma obra de arte é o mote para o desenvolvimento de um enredo que leva o narrador (ou o "eu") à história contemporânea, com menções à primeira guerra mundial.

"Sentei-me num sofá em uma esquina da exposição e, cansado, olhei para as telas infinitas com a sua límpidoscura beleza. "As terras africanas não vieram em vão para os arianos". Adormeci. Pareceu-me que eu estava no mar de tal forma que os joelhos pressionavam o fundo do oceano e os calcanhares mostravam-se em terra seca. Eu era colossal. A mesma muçulmana lutava e repelia aquelas mãos de alguém. Galípoli ficou coberta de olivas e parecia de prata. Eu rompi meus estreitos e ternos dedos sobre os rochedos da costa. A mesma máscara negra ela trazia no rosto. Uma fumaça azulada envolveu a beira-mar e toda ela era feita de fumaça. E então o "Queen Elizabeth" com a teia negra de seu cordame cortou as águas e tudo cobriu-se de bruma. Explosões de pólvora dos celeiros com- 
pletaram em renda negra a máscara da batalha, e através dos cortes brilhavam obstinadamente os olhos azuis da turca." $^{21}$

Num conto curtíssimo, Khlébnikov expõe sua proposta de uma narrativa vanguardista: como num quadro cubista de Filónov, o olhar sobre uma questão da história contemporânea nasce e finda-se na obra de arte. E no intervalo entre estes dois pontos, o próprio narrador torna-se parte grandiosa do cenário, compondo com sua figura colossal o quadro de guerra retratado. Nos contos de Khlébnikov, por meio do narrador e do próprio texto artístico, a história da Rússia e do mundo, as constantes guerras, as diferentes culturas vencem os limites de tempo e espaço e fundem-se num novo mundo, uno, coeso.

\section{O drama de Khlébnikov: um teatro para ser lido e ouvido}

O texto dramático costuma ser utilizado como base, fundamento das chamadas "supernarrativas" de Khlébnikov. Nestes textos, quase sempre fragmentos líricos, pequenos textos em prosa, considerações ensaísticas, são inseridos nem "falas", típicas do gênero dramático, tornando-o, assim, o gênero dominante no novo gênero proposto. Na supernarrativa mencionada anteriormente, Zanguézi, é esta estrutura que permite ao poeta demonstrar a maior parte das possibilidades da língua zaúm, já que ela acaba por ser utilizada como a língua dos diálogos entre pássaros (o zaúm da língua onomatopeica dos animais, ainda que as onomatopeias estejam repletas de referências à língua humana convencional, que fazem com que a língua "irracional" esbarre todo o tempo em sugestões de produção de sentido), entre deuses (esta, a manifestação zaúm mais próxima de uma destituição quase completa de sentido), a língua dos loucos e bêbados e outras tantas possibilidades. Estas experiências inovadoras são transportadas para seus textos dramáticos iso-

${ }^{21}$ Versão integral do conto. 
lados (como os que são apresentados nesta coletânea) e, ao mesmo tempo, estes retroalimentam as supernarrativas, levando a elas as características mais puras do gênero.

Independentemente das questões formais do gênero que alimentam a construção das supernarrativas, o mais importante elemento temático presente nelas e abordado de forma semelhante nos textos dramáticos "puros" é o tratamento da questão da "morte", que se espraia por vários níveis do enredo, permite ao autor fechamentos cíclicos e que, principalmente, possibilita a luta contra o tempo. A morte surge, irremediável, mas passível de ser vencida, se derrotada for a efemeridade do tempo. Ao final da supernarrativa Zanguézi, duas personagens leem num jornal a informação sobre a morte do protagonista Zanguézi,Mas este volta logo depois e, na fala final, profere, em terceira pessoa: "Zanguézi está vivo, foi tudo uma piada estúpida!".

Esta temática é explorada no texto dramático repleto de falas em forma de poemas líricos $O$ Erro da Morte e também em outros como Mundêsdofim e Senhora Lenin. São quase todos textos da primeira fase da produção de Khlébnikov, anterior às experiências com a fusão de gêneros, mas dentro de um momento bastante iconoclasta no que diz respeito às inovações com a linguagem e com alterações na estrutura tradicional dos gêneros. Se, em Senhora Lenin (1909-1912) uma relação amorosa que mal chegara a nascer, termina com a fala "tudo está morto, tudo morre", em Mundêsdofim (1912), a morte é vencida com a reversão mágica do tempo, na estória de um casal de velhos que, após fugirem da própria casa para não serem levados a um asilo, começam pouco a pouco a rejuvenescer, passar pelas fases anteriores de suas vidas, o crescimento dos filhos, 0 primeiro encontro ainda na escola, até cruzarem-se, no último ato, cada qual segurando um balão em seu carrinho de bebê. A vida retorna, em seu ciclo, mas sem o encerramento da morte. Apesar de extremamente curta, a peça é composta dentro da estrutura tradicional de cinco atos.

De qualquer maneira, os textos dramáticos de Khlébnikov não são feitos exatamente para a representação. É um traço formal inovador, pois uma das características fundamentais do drama é a sua completude como forma artística que só se dá no 
palco, na representação do texto. Em Senhora Lenin, a impossibilidade dá-se pelo deslocamento provocado por Khlébnikov ao lançar "vozes" nas posições de personagens. Estas vozes narram uma estória feita de ações, com traços cinematográficos, e de pouquíssimos diálogos. $O$ autor desloca também, desta maneira, a produção de sentidos das falas (onde tradicionalmente ocorrem, no teatro), para as personagens (ou vozes que são donas destas falas). Para que o sentido do narrado se complete, é necessário atentar para o sentido da voz. É o que pode ser observado já nas rubricas do início da peça:

Personagens:

Voz da Visão. Voz da Audição. Voz da Razão. Voz da Atenção. Voz da Memória. Voz do Medo. Voz do Tato. Voz da Vontade.

Tempo da ação: 2 dias na vida da Sra. Lenin, divididos em uma semana.

Escuridão. A ação passa-se diante de uma parede nua.

$1^{\circ} \mathrm{ATO}$

Voz da Visão. A chuva acabou agora e nos extremos curvados do escurecido jardim pendem as gotas do aguaceiro.

Voz da Audição. Silêncio. Ouve-se que alguém abre uma portinhola. Alguém anda pelos caminhos do jardim.

Voz da Razão. Para onde?

Voz da Compreensão. Aqui só se pode ir em uma direção.

Voz da Visão. Alguém se assustou, aves levantaram voo.

Voz da Compreensão. Foi o mesmo que abriu a porta.

Voz da Audição. $\quad$ O ar está repleto de um silvo assusta do, ressoam passos ruidosos.

Voz da Visão. Sim, está se aproximando com seu caminhar lento.

Na peça Os Deuses, a dificuldade de representação deve-se aos exercícios fonéticos impostos pela experiência de vanguarda russa: quase todas as falas da peça são compostas com utilização da língua zaúm, que serve a uma série de diálogos 
entre deuses de diversas culturas. Em termos de desenvolvimento da poética de Khlébnikov, esta peça parece seguir um caminho inverso ao das outras apresentadas, pois, ao que tudo indica, foi composta simultaneamente à composição de sua última obra, Zanguézi. Esta peça está profundamente ligada à supernarrativa, pois muitas das personagens e mesmo falas dos deuses surgem de forma quase idêntica no interior de Zanguézi. Os Deuses configura-se, assim, como um projeto intimamente ligado à última obra, projeto no qual Khlébnikov desenvolve a experiência zaúm dentro de uma de suas manifestações, justamente aquela mais próxima da criação de uma língua fonética quase que destituída de sentido.

Juno ${ }^{22}$ : Houve, ontem, um beijo.

Múri guri rikokó.

(gravando a semana e a data nos ombros de madeira do deus).

E este é o nome Zi-zi rízi! (grava com uma faquinha). Siokúki - sisisí!

Unkulunkulu ${ }^{23}$ :pertch ${ }^{24 !}$ Khartch ${ }^{25}$ ! Zortch ${ }^{26}$

Bufa e sai. O caderno de notas da grandiosa e bela deusa, traços do amor em letras rabiscadas no caderno. Caem flocos de neve.

Juno: Khanziopo ${ }^{27}$ ! Estou com frio!

Perun ${ }^{28}$ dá a ela um casado de pele de urso negro das florestas da Sibéria. A deusa friorenta protege-se da neve com ele. Flocos de neve.

\footnotetext{
${ }^{22}$ Juno: na mitologia romana, mulher de Júpiter e rainha dos deuses.

${ }^{23}$ Unkulunkulu é o deus supremo da criação para a mitologia Zulu do sul da África. Teria nascido dos juncos, talvez daí a referência do poeta a um "corpo de madeira" do deus.

${ }^{24}$ Remete a "pértchik": referência a algo picante, apimentado.

${ }^{25}$ Remete a khartchí: coisa comestível, palavra genérica para coisas comestíveis.

${ }^{26}$ Associação com kórtch: convulsão.

${ }^{27}$ Assemelha-se a uma interjeição que se inicia pela palavra "khan" (líder dos mongóis, como Gengis-khan).

${ }^{28}$ Perun ou Perunú: deus dos raios e das tempestades na mitologia eslava antiga, representado com a cabeça de prata e a barba dourada.
} 
$V_{\text {ênu }}{ }^{29}$ : En-kéntchi! A mão de Osíris foi encontrada Hoje por mim nas pedras da cachoeira.

En-kéntchi! Zibgár ${ }^{30}$, zorgám ${ }^{31}$ ! Dzug-zag!

Mentch! Mantch! Miu!

Beijem! Zeb zub diobé! tsitsiríki tsátsa!

Beijem!

sofrimentos!

Com o pente da boca raspem os cabelos dos

Sikikíkhi khazadero ${ }^{32}$.

Como é possível observar, no fragmento acima, os exercícios fonéticos da língua zaúm são entremeados pela língua russa, que dá suporte a breves relações de sentido que vão, pouco a pouco, compondo entre as falas as pistas para que o leitor acompanhe os diálogos, ainda que de forma telegráfica. Apesar deste traço criativo, Khlébnikov desenvolve o texto dramático dentro de uma composição de atos que, de alguma maneira, ainda está inspirada nas formas tradicionais de realização do gênero.

\section{Khlébnikov ensaísta: o artista pensa a arte de seu tempo}

No conjunto da obra de Khlébnikov existe um considerável número de ensaios e eles apresentam características tão peculiares quanto todo o resto de sua produção. Os ensaios de Khlébnikov podem ser divididos em dois grandes grupos: num

\footnotetext{
${ }^{29}$ Vênus: deusa romana do amor e da beleza, equivalente a Afrodite na mitologia grega.

30 "gar", na palavra, lembra a ideia de calor, fogo, algo que queima (antecedida por um tipo de prefixo inventado pelo poeta, "zib").

31 Sentidos internos a que remete: "zórkii" (penetrante, agudo) + "órgan" (órgão) + "orgazm" (orgasmo).

${ }^{32}$ Aproximação à palavra "khazavat" (guerra santa islâmica, como a jikhad) + verbo "zadet" (ofender, agredir).
} 
primeiro, pode-se identificar textos que tratam da própria literatura e da linguagem literária (Khlébnikov discute, neles: a literatura de seu tempo, os movimentos estéticos de vanguarda, as relações com a tradição, os métodos de elaboração da língua zaum e de outras inovações estéticas); no segundo grupo estão os ensaios em tom profético, nos quais são utilizados cálculos matemáticos (que muitas vezes servem a associações com a própria literatura) utilizados algumas vezes para previsões sobre o futuro, outras para analisar fatos do passado e, em todos os casos, surge uma tentativa mais profunda de identificar um ritmo universal, capaz de unir passado e futuro, tempo e espaço. Muitos textos deste último grupo são agrupados em uma obra, sob o título "As Tábuas do Destino"33. Um dos fragmentos mais exemplares das tábuas do destino, com seus cálculos matemáticos, está presente também na obra-síntese Zanguézi. Em tom autobiográfico que remete ao próprio autor, o profeta Zanguézi apresenta a uma longa explanação sobre as "Tábuas do Destino" (as anotações são encontradas por uma pessoa e lidas aos outros). Nela, tenta demonstrar como os cálculos propostos podem permitir identificar movimentos regulares em fatos históricos do passado (tanto da história mundial, quanto da história da Rússia), a partir de uma fórmula inicial, na qual a inserção de determinada data permitiria prever o acontecimento de outro fato importante num intervalo regular dado por ela:

“ $2^{\circ}$ passante. "As tábuas do destino! Eu vos talharei em letras da noite negra, tábuas do destino!

Três números! O meu eu da juventude, o meu eu da velhice, o meu eu da meia-idade: juntos sigamos pelo pó dos caminhos!

$105+104+115=742$ anos e 34 dias. Leiam, olhos, a lei da ruína dos impérios.

\footnotetext{
${ }^{33}$ B. M. Vladímirski, no artigo "'Tchislá' v Tvórtchestve Khlébnikova - probléma avtokolebátel'nykh tsíklov v sotsiál'nykh sistémakh" ("Os 'Números' na Obra de Khlébnikov - o problema dos ciclos auto-oscilantes nos sistemas sociais", em Mir Velimíra Khlébnikova, 2000, pp. 723-732), estuda a concepção de Khlébnikov de uma 'filosofia matemática da história', por meio de suas 'Leis do Tempo'. Verifica que Khlébnikov trabalha com a associação, em cálculos matemáticos, de diferentes sistemas: seus cálculos relacionam as oscilações sócio-históricas e culturais na linha do tempo às oscilações biológicas no ritmo cíclico dos ecossistemas. Estabelece, então, uma analogia de base matemática entre o ritmo das mudanças sócio-históricas e os ciclos naturais.
} 
Eis a equação: $\mathrm{X}=\mathrm{k}+\mathrm{n}(105+104+\mathrm{ll} 5)-(102-(2 \mathrm{n}-1)$ 11) dias.

$\mathrm{k}$ é o ponto de partida no tempo, a marcha dos romanos sobre o leste, a batalha do Ácio. O Egito rendeu-se a Roma. Isto foi em 2 de Setembro do $31^{\circ}$ ano a.C.

Com $\mathrm{n}=\mathrm{l}$, o valor de xis na equação da ruína dos povos será o seguinte: $\mathrm{X}=21$ de Julho de 711 , ou o dia em que a Espanha perdeu sua imponência, conquistada pelos árabes. Caiu a imponente Espanha!"

Assim como o próprio Khlébnikov ouvia críticas céticas aos resultados de seus cálculos proféticos, Zanguézi será também desacreditado, ao fim do fragmento, por um dos ouvintes: "obscuro e incompreensível. Mas, de qualquer jeito, vê-se aí a unha do leão! Dá pra perceber. Um pedacinho de papel onde estão gravados os destinos dos povos para quem tenha olhos de ver! $!^{134}$.

Os planos filosóficos propostos nos cálculos matemáticos do poeta são claros: a utopia de uma harmonia universal estaria na concretização de um "governo sobre o tempo". O controle sobre o tempo representaria o impossível controle absoluto sobre o processo histórico, desde o passado mais remoto até o futuro mais distante, rompendo assim a linearidade das barreiras temporais.

Em ensaios como "Púchkin e as puras leis do tempo" e "A equação da vida de Gógol", ambos extraídos do grupo "As Tábuas do Destino", as complexas fórmulas matemáticas de Khlébnikov servem para identificar um ritmo regular nos inter-

\footnotetext{
34 Não foram poucos os textos de Khlébnikov nos quais expôs tais teorias. Em Zakón Pokolénii (A Lei das Gerações, in: Tvoriéniia, 1987, pp. 648-652), de 1914, associa em cálculos matemáticos os fatos ocorridos em vidas de grandes figuras da história e da vida cultural russa. Por exemplo, são mencionados o anarquista Bakúnin, o escritor Alexei Tolstói e outros. Por meio de cálculos com base, por exemplo, em datas de nascimento e morte, procura indicar certos movimentos regulares nos fatos históricos. Sob o mesmo método escreve, no mesmo ano de 1914, o artigoSpor o Pérvenstve (A Disputa pela Primazia, in: Tvoriéniia, 1987, pp. 646-648). Porém, uma das mais impressionantes e detalhadas explanações sobre este método está no ensaio Utchítel' i Utcheník - o Slovákh, Gorodákh i Naródakh(O Mestre e o Aluno - sobre as Palavras, as Cidades e os Povos, in: Tvoriéniia, 1987, pp. 584-593), escrito ainda em 1912, ou seja, dez anos antes da realização de Zanguézi. 0 texto desenvolve-se como um diálogo entre mestre e aluno e nele são apresentadas até mesmo ilustrações gráficas em tabelas, nas quais são desenvolvidas as relações matemáticas sobre dados históricos para esclarecimento do método.
} 
valos de tempo de fatos biográficos e de momentos de produção literária na vida dos escritores da tradição. Aqui, os cálculos matemáticos, em tom quase místico, estão associados ao estudo da literatura.

Já os ensaios de Khlébnikov voltados para a literatura, tendem, muitas vezes, ao tom de manifesto (uma característica comum à época das vanguardas em todo o mundo). $\mathrm{O}$ objeto de comentário mais recorrente é o trabalho com a linguagem. No caso de Khlébnikov e do contexto das vanguardas russas, este interesse recai muitas vezes sobre a língua zaúm ou, em termos mais amplos, às possibilidades de operar criativamente sobre a linguagem. É o que se pode observar em "Sobre a poesia contemporânea":

"A palavra vive uma vida dupla.

Ela simplesmente cresce como uma planta, produz a drusa das pedras sonoras adjacentes a ela, e então o início do som vive a autoespiral da vida, mas uma parte da razão, chamada palavra, fica nas sombras; ou a palavra, então, vem em socorro à razão e o som deixa de ser "onigrandioso" e autocrático: o som torna-se "nome" e docilmente executa as ordens da razão; este é, então, o segundo jogo eterno que floresce a si mesmo na drusa de semelhantes pedras.

A razão diz "obedeço" ao som, o som puro o diz à pura razão.

Esta luta de mundos, uma luta de dois poderes, que sempre tem lugar na palavra, proporciona a vida dupla da língua: dois círculos de estrelas aladas." ${ }^{35}$

A partir destas considerações gerais sobre o cerne da criação poética, Khlébnikov traz uma série de exemplos de inovações poéticas propostas por outros poetas de vanguarda e as relaciona com a tradição, buscando claramente identificar um movimento histórico de criação, que vem da tradição e chega até a vanguarda, e que tem relação direta com o maior ou menor grau de articulação dos elementos linguísticos na literatura. Repletos de metáforas, imagens poéticas (às vezes bastante subjetivas, muito pouco precisas), neologismos e estranha-

${ }^{35}$ Fragmento inicial do ensaio, de 1919 
mentos sintáticos, os ensaios khlebnikovianos trazem para um gênero fundamentalmente analítico a principal marca da obra do escritor: a criatividade poética indomável, como fator determinante da própria forma de pensar e entender o mundo e a arte de seu tempo.

\section{Referências bibliográficas}

BARAN, H.. O Khlébnikove. Kontéksty, istótchniki, mífy [Sobre Khlébnikov. Contextos, fontes, mitos]. Moscou: RGGU, 2007. BRIK, Óssip. "O Khlébnikove" [Sobre Khlébnikov], in: Mir Velimíra Khlébnikova [O Mundo de Velimír Khlébnikov]. Moscou: Iazykí Rússkoi Kultúry, 2000, pp. 255-262.

CAMPOS, Augusto de. "O Colombo dos novos continentes poéticos". In À Margem da Margem. São Paulo: Companhia das Letras, 1989, pp. 87-95.

CAMPOS, Augusto e Haroldo e SCHNAIDERMAN, Bóris (org. e trad.). Poesia Russa Moderna. São Paulo: Brasiliense, 1985.

DRÁVITCH, A.. "Khlébnikov - mundi constructor" in: Mir Velimíra Khlébnikova [O Mundo de Velimír Khlébnikov]. Moscou: Iazykí Rússkoi Kultúry, 2000, pp. 490-502.

DUGÁNOV, R. V.. Velimír Khlébnikov - Priróda Tvórtchestva [Velimír Khlébnikov - A Natureza da Criação]. Moscou: Soviétskii Pisátel, 1990.

"Krátkoe 'Iskússtvo Poézii' Khlébnikova" [Breve "Arte Poética" de Khlébnikov], in: Izvéstia AN URSS, Sériia literatury i iazyka [Notícias AN URSS, Série de literatura e Língua], tomo XXXIII, número 5, Moscou, 1974, pp. 418-427.

Velimír Khlébnikov i Russkaia Literatura [Velimír Khlébnikov e a Literatura Russa]. Moscou: Progress-Pleiada, 2008.

GASPÁROV, M. L.. "Stchitálka Bógov - O piésse V. Khlébnikova 'Bógui"' [A Leitura dos Deuses - Sobre a Peça de V. Khlébnikov "Os deuses"], in: Mir Velimíra Khlébnikova [O Mundo de Velimír Khlébnikov]. Moscou: Iazykí Rússkoi Kultúry, 2000, pp. 279-293. GRIGÓRIEV, V. P.."K Poétike i Estétike Avangarda” [Para a Poética e Estética da Vanguarda], in: Budetlianín. Moscou: Iazykí Rússkoi Kultury, 2000, pp. 737-740. 
"'Bezúmnyi, no Izumítelnyi'. Velimír Khlébnikov - Nach Einchtein ot Gumanitarii?" [Louco, mas Admirável.Velimír Khlébnikov - Nosso Einstein das Ciências Humanas?], in: AUNIS, número 6, Moscou, 2005, pp. 495-502.

IMPOSTI, Gabriella. '"Zanguezi'. La lengua degli dei. Fonosimbolismo e zaúm", in: Zaúmnyi Futurízm i Dadaízm v Rússkoi Kultúrye [Futurismo zaúm e Dadaismo na Cultura Russa]. Bern, Berlin, Frankfurt, New York, Paris, Wien: Lang, 1991, pp. 103-115. ITCHIN, Kornelia. "Utópia Khlébnikova i Zamýsel 'Ideálnovo Gosudárstva' u Platona" [A Utopia de Khlébnikov e a Idéia de "Estado Ideal"de Platão], in: Khudójestvennyi Tekst kak Dinamitchéskaja Sistema [O Texto Artístico como Sistema Dinâmico] . Moscou: Azbukóvniki, 2006, pp. 524-534.

JAKOBSON, Roman. "Noviéichaia Rússkaia Poézia. Nabróssok Piérvii: Pódstupyi k Khliébnikovu" [Novíssima Poesia Russa. Primeiro esboço: aproximações a Khlébnikov], in: Mir Velimíra Khlébnikova [O Mundo de Velimír Khlébnikov]. Moscou: Iazykí Rússkoi Kultúry, 2000, pp. 20-77.

KHÁRDJIEV, N. I..Ot Maiakóvskovo do Krutchônikh: Izbránnye Rabóty o Rússkom Futurízme [Trabalhos Escolhidos sobre o Futurismo Russo]. Moscou: Guilea, 2006.

KHLÉBNIKOV, Velimír. Sobránie Sotchiniénii v trekh tomákh [Obra Reunida em Três Tomos]. São Petersburgo: Sankt Peterburg, 2001.

Sobránie Sotchiniénii v 6 tomákh [Obra Reunida em 6 Tomos]. Moscou: Naslédie, 2000.

Tvoriénia [Obras]. Moscou: Soviétskii Pisátel,1986.

Sobránie Sotchiniénii v chesti tomákh [Obra Reunida

em Seis Tomos]. São Petersburgo: Sankt Peterburg, 2001. Poéziia. Proza. Dramatítcheskie Proizvedeniia. Publitsístika [Poesia. Prosa. Obras Dramáticas. Artigos]. Moscou: Slovo, 2001.

V. V. Khlébnikov: Stikhotvoriéniia. Poémy. Drámy. Proza [V. V. Khlébnikov: Versos. Poemas. Dramas. Prosa.]. Moscou: Sov. Rossíia, 1986 1977.

Ka (trad. Aurora F. Bernardini). São Paulo: Perspectiva, The King of Time - Selected Writings of the Russian Futurism (trad. Paul Schmidt). Cambridge: Harvard University Press, 1990. 
“"Bezúmnyi, no Izumítelnyi'. Velimír Khlébnikov - Nach Einchtein ot Gumanitarii?" [Louco, mas Admirável.Velimír Khlébnikov - Nosso Einstein das Ciências Humanas?], in: AUNIS, número 6, Moscou, 2005, pp. 495-502.

IMPOSTI, Gabriella. "'Zanguezi'. La lengua degli dei. Fonosimbolismo e zaúm", in: Zaúmnyi Futurízm i Dadaízm v Rússkoi Kultúrye [Futurismo zaúm e Dadaismo na Cultura Russa]. Bern, Berlin, Frankfurt, New York, Paris, Wien: Lang, 1991, pp. 103-115. ITCHIN, Kornelia. "Utópia Khlébnikova i Zamýsel 'Ideálnovo Gosudárstva' u Platona" [A Utopia de Khlébnikov e a Idéia de "Estado Ideal"de Platão], in: Khudójestvennyi Tekst kak Dinamitchéskaja Sistema [O Texto Artístico como Sistema Dinâmico] . Moscou: Azbukóvniki, 2006, pp. 524-534.

JAKOBSON, Roman. "Noviéichaia Rússkaia Poézia. Nabróssok Piérvii: Pódstupyi k Khliébnikovu" [Novíssima Poesia Russa. Primeiro esboço: aproximações a Khlébnikov], in: Mir Velimíra Khlébnikova [O Mundo de Velimír Khlébnikov]. Moscou: Iazykí Rússkoi Kultúry, 2000, pp. 20-77.

KHÁRDJIEV, N. I..Ot Maiakóvskovo do Krutchônikh: Izbránnye Rabóty o Rússkom Futurízme [Trabalhos Escolhidos sobre o Futurismo Russo]. Moscou: Guilea, 2006.

KHLÉBNIKOV, Velimír. Sobránie Sotchiniénii v trekh tomákh [Obra Reunida em Três Tomos]. São Petersburgo: Sankt Peterburg, 2001.

Sobránie Sotchiniénii v 6 tomákh [Obra Reunida em 6 Tomos]. Moscou: Naslédie, 2000.

Tvoriénia [Obras]. Moscou: Soviétskii Pisátel,1986.

Sobránie Sotchiniénii v chesti tomákh [Obra Reunida

em Seis Tomos]. São Petersburgo: Sankt Peterburg, 2001. Poéziia. Proza. Dramatítcheskie Proizvedeniia. Publitsístika [Poesia. Prosa. Obras Dramáticas. Artigos]. Moscou: Slovo, 2001.

V. V. Khlébnikov: Stikhotvoriéniia. Poémy. Drámy. Proza [V. V. Khlébnikov: Versos. Poemas. Dramas. Prosa.]. Moscou: Sov. Rossíia, 1986 1977.

Ka (trad. Aurora F. Bernardini). São Paulo: Perspectiva, The King of Time - Selected Writings of the Russian Futurism (trad. Paul Schmidt). Cambridge: Harvard University Press, 1990. 
Prose, Plays, and Supersagas II (trad. Paul Schmidt). Cambridge: Harvard University Press, 1989.

KRUTCHÔNIKH, Alekséi. K Istórii Rússkovo Futurízma - Vospominániia i Dokuménty [Para a História do Futurismo Russo - Memórias e Documentos]. Moscou: Guilea, 2006.

"Declarátsiia Zaúmnovo Iazyká" [Declaração da Língua Zaúm]. Revista Iskússtvo, nº 1, Baku, 1921, p. 16.

LANNE, Jean-Claude. 'Les sources de lazaúm' chez Krucenych et Chlebnikov", in: Zaúmnyi Futurízm i Dadaízm v Rússkoi Kultúrye [Futurismo zaúm e Dadaismo na Cultura Russa]. Bern, Berlin, Frankfurt, New York, Paris, Wien: Lang, 1991, pp. 21-55. LÓTMAN, Iúri M. La Semiosfera I - Semiótica de la Cultura y del Texto. Madrid: Ediciones Cátedra, 1996.

La Semiosfera II - Semiótica de la Cultura, del Texto, de la Conducta y del Espacio. Madrid: Ediciones Cátedra, 1996. MÁRKOV, V. Russian Futurism: a History. USA: University of California, 2006.

"O Khlébnikove (popýtka apológuii i soprotivléniia)" [Sobre Khlébnikov (tentativa de apologia e resistência)], in: KHLÉBNIKOV, V., Sobránie Sotchiniénii v trekh tomákh [Obra Reunida em Três Tomos). Vol. I. São Petersburgo: Sankt Petersburg, 2001, pp. 06-40.

MENEZES, Philadelpho (org.). Poesia Sonora. São Paulo: EDUC - Editora da PUC/SP, 1992.

MOELLER-SALLY, Betsy F.. "Masks of the Prophet in the Work of Velimír Khlebnikov: Pushkin and Nietzsche." In: The Russian Review. Vol. 55, $\mathrm{N}^{\circ} 2$, April 1996. Columbus: The Ohio State University Press, 1996, pp. 201-225.

PÁCHKIN, D. A.. Fenomén Smérti v Tiékstakh Velimíra Khlébnikova: Nekatórye Aspiékty Problémy [O Fenômeno da Morte nos Textos de Velimír Khlébnikov: Alguns Aspectos do Problema]. Tiumén: Tiuménskovo Gosudárstvennovo Universitéta, 2002. PÁRNIS, A. E.. "Nezamétchennyi Iubiléi Koroliá Vrémeni" [O Aniversário Despercebido do Rei do Tempo], in: EX LIBRIS, Moscou, Novembro de 2005, p. 02-06.

POLIÁKOV, Vladímir. "Knígui Rússkovo Kubofuturízma" [Livros do Cubofuturismo Russo]. Moscou: Guilea, 2007.

SCHNAIDERMAN, Bóris. A Poética de Maiakóvski. São Paulo: Perspectiva, 1971.

STÁRKINA, Sofia. Velimír Khlébnikov. Moscou: Molodáia Gvárdia, 2007. 
STEPÁNOV, N. L.. Velimír Khlébnikov. Jízn i Tvórtchestvo [Velimír Khlébnikov - Vida e Obra]. Moscou: Soviétskii Pisátel, 1975. TCHEKHOV, A. O Beijo e Outras Histórias (trad. Boris Schnaiderman). São Paulo: Editora 34, 2006.

TINIÁNOV, Iúri. "O Khlébnikove" [Sobre Khlébnikov], in: Sobránie Sotchiniénii v trekh tomákh [Obra Reunida em Três Tomos]. São Petersburgo: Sankt Petersburg, 2001, pp. 05-12.

"Chlèbnikov". In: Avanguardia e Tradizione. Bari/ Itália:

Dedalo Libri, 1968.

VLADÍMIRSKI, B. M.. "'Tchislá' v Tvórtchestve Khlébnikova probléma avtokolebátel'nykh tsíklov v sotsiálnykh sistémakh" [Os "Números" na Obra de Khlébnikov - o problema dos ciclos auto-oscilantes nos sistemas sociais], in: Mir Velimíra Khlébnikova. [O Mundo de Velimír Khlébnikov]. Moscou: Iazykí Rússkoi Kultúry, 2000, pp. 723-732. 